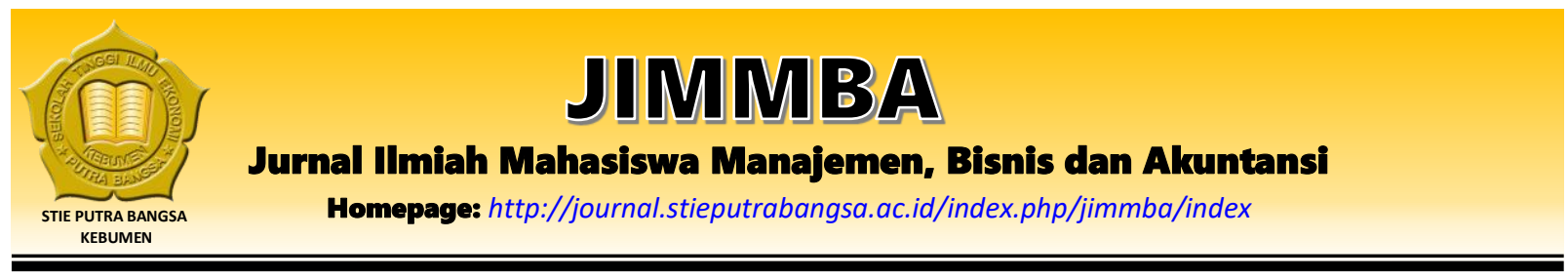

\title{
Perancangan Mukena UKM DW Kreasi untuk Muslimah
}

\author{
Suci Mutiara Bilqis ${ }^{1}$, Noverdi Bross ${ }^{2}$, Bayyinah Nurul Haq ${ }^{3}$ \\ 1,2,3 Universitas Trilogi \\ Sucimutiarabilqis@gmail.com ${ }^{1}$ \\ Noverdi.bross@universitas-trilogi.ac.id ${ }^{2}$ \\ Bayyinah.nh@universitas-trilogi.ac.id ${ }^{3}$
}

\begin{tabular}{l}
\multicolumn{1}{c}{ ARTICLE INFO } \\
\hline \\
Article History: \\
Received: July $18^{\text {th }} 2020$ \\
Accepted: August $1^{\text {st }} 2020$ \\
Published: August $31^{\text {st }} 2020$ \\
Keywords: \\
UKM, Dw Kreasi, Mukena, \\
Tas, Sajadah
\end{tabular}

Tas, Sajadah

\begin{abstract}
Salah satu masalah yang dihadapi UKM bidang fashion adalah desain yang tidak sesuai dengan selera pasar. DW Kreasi adalah UKM yang bergerak dibidang garmen, produk yang dihasilkan adalah gamis, jilbab dan mukena. Produk mukena memiliki potensi penjualan yang baik dan perubahan trend desain mukena cenderung lambat. Kondisi ini membutuhkan desain mukena yang menawarkan fungsi bukan hanya model semata. Perancangan mukena UKM Dw Kreasi dengan penambahan fungsi pada mukena Dw Kreasi yaitu pada tas yang multifungsi yaitu selain sebagai tempat penyimpanan mukena juga dapat digunakan sebagai sajadah sehingga mukena dapat efisien jika digunakan untuk berpergian. Renda dengan warna senada dengan bahan mukena yang dikombinasikan pada mukena akan memberi nilai estetika sehingga diharapkan dapat meningkatkan harga jual mukena Dw Kreasi. Tas yang juga multifungsi yang akan memenuhi kebutuhan konsumen sehingga diharapkan dapat meningkatkan penjualan.
\end{abstract}

\section{Pendahuluan}

Usaha Kecil Menengah (UKM) yang bergerak di bidang busana (fashion) sampai saat ini belum bekerjasama dalam memasarkan produknya. Hal ini dilihat dari perkembangan UKM fashion yang bergerak sendiri-sendiri di seluruh Indonesia. Dari data Kementerian Koperasi dan UKM, jumlah koperasi selama 2013 sebanyak 40 juta. Sedangkan UKM yang bergerak di bidang fashion ada 3,5 juta. (https://www.tribunnews.com/tag/usaha-kecil-menengah$\underline{\mathrm{ukm}}$ ). Mukena dapat dikategorikan sebagai produk garmen, yang masuk dalam kategori pakaian fungsional karena memiliki fungsi sebagai pakaian yang digunakan untuk beribadah untuk yang beragama islam. 
DW Kreasi adalah salah satu UKM yang berada di Bogor, Jawa Barat. Selain mukena, DW Kreasi juga memproduksi jilbab dan gamis. Diantara ke tiga produk tersebut mukena merupakan produk yang memiliki peluang bertahan di pasaran lebih tinggi dibandingkan dengan produk lainnya. Karena, setiap bulan trend selalu berubah-ubah sedangkan model mukena sangat monoton meski begitu peminat nya sangat banyak oleh karena itu diperlukan pengembangan produk dengan desain yang menarik sehingga dapat memuaskan konsumen.

\section{Tinjauan Pustaka}

\section{Industri Garmen}

Industri pakaian jadi atau garment tidak bisa terlepas dari industri tekstil karena untuk membuat pakaian jadi memerlukan hasil-hasil dari industri tekstildi sector lainnya, yaitu sektor upstream yang menghasilkan produk benang dan sektor industri midstream yang memproduksi kain sebagai bahan bakunya. Industri garment merupakan bagian dari industri tekstil dan produk tekstil yang telah berkembang di Indonesia. Pakaian jadi/clothing/garment adalah hasil pengolahan lebih lanjut dari tekstil, berbagai jenis pakaian yang siap pakai (ready to wear) dalam berbagai ukuran standar, antara lain pakaian pria dan wanita baik dewasa, remaja dan anak-anak, pakaian pelindung, pakaian seragam, pakaian olah raga, dan lain-lain. (Siswoyo, Andika Aji. 2017:47)

\section{Perancangan}

Menurut Kamus Besar Bahasa Indonesia, definisi perancangan yaitu proses, cara, cerbuatan merancang. Merancang yaitu mengatur segala sesuatu sebelum bertindak, mengerjakan, atau merencanakan. Perancangan adalah sebuah proses untuk mendefinisikan sesuatu yang akan dikerjakan dengan mengunakan teknik yang bervariasi serta didalam nya melibatkan deskripsi mengenai arsitektur serta detail mengenai komponen dan juga keterbatasan yang akan dialami dalam proses pengerjaan nya. (Soetam Rizky, 2011 : 140).

\section{Redesain}

Menurut Helmi. 2008, Redesain merupakan perencanaan dan perancangan kembali suatu karya agar tercapai tujuan tertentu. Redesain berasal dari bahasa Inggris yaitu Redesign yang berarti mendesain kembali atau perencanaan kembali. Dapat juga berarti menata kembali sesuatu yang sudah tidak berfungsi lagi sebagai mana mestinya (Depdikbud, 1996 : 3). Redesain adalah suatu proses untuk menentukan tindakan-tindakan dimasa depan yang sesuai, melalui suatu tahapan pemilihan. (Churchman and Ackolt dalam Irvan, 2002 : 1$1)$.

\section{Mukena}

Menurut KBBI mukena/mu ke na/ n kain selubung berjahit (biasanya berwarna putih) untuk menutup aurat wanita Islam pada waktu shalat; telekung. Mukena adalah busana perlengkapan shalat untuk perempuan muslim khas di Indonesia, sebenarnya dalam Islam tidak ada kaidah terperinci perihal pakaian seperti apa yang seharusnya digunakan untuk 
shalat, hanya ada prinsip-prinsip umum bahwa busana untuk shalat hendaknya menutupi aurat dan bersih dari noda atau kotoran.

Mukena adalah komoditas budaya khas di Indonesia, konon merupakan hasil penyesuaian yang dilakukan oleh para wali zaman dahulu berdasarkan dengan prinsip dalam Agama Islam. Prinsip Agama Islam menerangkan bahwa muslimah harus berpakaian bersih, rapi, tidak menyerupai pakaian wanita kafir, tidak menyerupai laki-laki, kain tidak menerawang, tidak diberi wewangian dan menutupi aurat. (http:/ /journals.an1mage.net/index.php/ajsk).

Terkait menutup aurat menurut hukum Islam terkait desain busana muslimah dibahas oleh (Surtiretna, Nina., Rufaidah, Anne, (1995) dalam Kurniawan \& Indriati ( :47) adalah menutup aurat yang meliputi kepala, rambut, leher, dada dan seluruh tubuh kecuali muka dan tangan. Selain bagian yang harus tertutup, siluet dan bentuk pakaian haruslah longgar atau tidak membentuk tubuh. Tidak membentuk tubuh termasuk didalamnya menggunakan bahan yang tidak menerawang, tidak membentuk/mencetak ebntuk tubuh pemakainya.

Bahan yang tidak menerawang namun ketebalannya cukup nyaman untuk digunakan di daerah topis adalah BSY atau Bi Shrinkage Yarn. Detail dari bahan ini adalah 100\% polyster fabric dengan finishing menggunakan dua jenis polyester filament yang berbeda sehingga menjadikan bahan yang halus, lembut dan tidak panas seperti bahan katun yang pastinya mudah dijahit. BSY adalah salah satu bahan yang cocok untuk printing textile karena selain bahan yang lembut bahkan tidak panas mempunyai karakter bahan yang hasil printnya mempunyai warna yang cerah, untuk area bersih saat di print nya sekitar 140-145 cm, dengan menggunakan lebar layout cetak $150 \mathrm{~cm}$. Biasanya estimasi bahan ini mengalami penyusutan sebesar 0,5 \% bahkan bisa juga sampai 1-2 \%. Selain itu juga, kegunaan bahan ini biasanya untuk dijadikan sebagai sarung bantal atau sofa, mukena, seragam batik, lapisan selimut atau bisa juga dijadikan sebagai sprei. (https://www.tekstilprinting.com/fabrics/bsy).

\section{Metode Penelitian}

Pada penelitian ini, metode yang digunakan adalah metode penelitian secara kualitatif. Penelitian kualitatif merupakan kajian berbagai jenis materi empiris, seperti studi kasus, wawancara, pengamatan, interaksional, dan teks visual. Penelitian kualitatif adalah penelitian yang bermaksud untuk memahami fenomena tentang apa yang dialami oleh subjek penelitian secara holistic, dan dengan cara deskripsi dalam bentuk kata-kata dan bahasa, pada suatu konteks khusus yang alamiah dan dengan memanfaatkan berbagai metode alamiah (Moleong, $2007: 6)$.

\section{Teknik Pengumpulan Data}

Metode pengumpulan data merupakan langkah yang paling utama dalam penelitian, karena tujuan utama dari penelitian adalah mendapatkan data. Tanpa mengetahui metode pengumpulan data maka penelitian tidak akan mendapatkan data yang memenuhi standar data yang ditetapkan (Sugiyono dalam Purwono, 2014). Ada beberapa cara dalam pengumpulan data yaitu : 
1. Data primer berupa pengumpulan data secara langsung di lapangan dengan wawancara. Wawancara dilakukan pada Owner sebagai pemilik UKM Dw Kreasi terkait bisnis nya.

2. Data sekunder berupa data literatur yang diperoleh dari buku, jurnal dan laporan tugas akhir. Sumber data banyak diperoleh dari jurnal dan buku untuk mengetahui teori perancangan, mukena, dan lain-lain.

\title{
Teknik Analisis
}

Teknik Analisis data yang akan digunakan pada perancangan ini adalah:

\begin{abstract}
Analisis SWOT
Analisis SWOT dalam (Rangkuti, 2016 : 20) adalah analisis kondisi internal maupun eksternal suatu organisasi yang selanjutnya akan digunakan sebagai dasar untuk merancang strategi dan program kerja. Analisis internal meliputi peniaian terhadap faktor kekuatan (Strength) dan kelemahan (Weakness). Sementara, analisis eksternal mencakup faktor peluang (Opportunity) dan tantangan (Threaths).
\end{abstract}

\section{Space Matriks}

Analisis space matriks merupakan salah satu alat untuk menetapkan strategi bisnis yang meliputi 4 variabel atau dimensi strategis dari suatu perusahaan. Keempat dimensi tersebut adalah kekuatan keuangan, keunggulan bersaing, stabilitas lingkungan bisnis, dan daya tarik industri.

\section{Matriks IFAS \& EFAS}

Internal Factors Analysis Summary (IFAS) merupakan alat yang tepat digunakan untuk menyajikan analisa kondisi internal ke dalam matrik yang telah diberi bobot dan rating untuk mengetahui bagaimana perusahaan tersebut bereaksi terhadap faktor-faktor strategis internal (Rangkuti, 2016:28). Eksternal Factors Analysis Summary (EFAS) dalam (Rangkuti, 2016:25) merupakan alat analisa yang menyajikan secara sistematis mengenai kondisi eksternal perusahaan ke dalam matrik yang telah diberi bobot dan rating untuk mengetahui bagaimana perusahaan tersebut bereaksi terhadap faktor- faktor strategis eksternalnya.

\section{Matriks BCG (Boston Consulting Group)}

Matriks Boston Consulting Group (BCG) secara grafis menunjukkan perbedaan di antara berbagai divisi dalam posisi pangsa pasar relatif dan tingkat pertumbuhan industri. Matriks BCG menurut (Amirullah, 2015:11) memungkinkan organisasi multidivisi untuk mengelola portofolio bisnisnya dengan mempertimbangkan posisi pangsa pasar relatif dan tingkat pertumbuhan industri di masing-masing divisi relatif terdahap divisi lain dalam organisasi. Posisi pangsa pasar relatif (relative market share position) didefinisikan sebagai rasio dari pangsa pasar satu divisi tertentu terhadap pangsa pasar yang dimiliki oleh pesaing terbesar dalam industri tersebut. Matriks Boston Consulting Group (BCG) membagi sebuah daerah dengan dua garis yaitu vertikal dan horizontal menjadi empat daerah (kuadran). Empat daerah tersebut diberi nama yaitu tanda tanya (question 
mark), bintang (star), sapi perah (cash cow) dan anjing (dog). Garis horizontal menggambarkan posisi relatif dari pangsa pasar yang dikuasai perusahaan, sedangkan garis vertikal melukiskan tingkat pertumbuhan pangsa pasar.

\section{Benchmarking}

Benchmarking dalam (Paulus, 2013:18) adalah proses pengukuran secara berkesinambungan dan membandingkan satu atau lebih bisnis proses perusahaan dengan perusahaan yang terbaik di proses bisnis tersebut, untuk mendapatkan informasi yang dapat membantu perusahaan untuk mengidentifikasi dan mengiplementasikan peningkatan proses bisnis (Paulus, 2013:16). Benchmarking sebagai suatu proses pengukuran terus menerus atas produk, jasa dan tata cara perusahaan terhadap pesaing yang terkuat. Benchmarking juga merupakan suatu proses yang membandingkan dan mengukur kinerja suatu perusahaan dengan perusahaan lain guna mendapatkan keuntungan informasi yang akan digunakan untuk perbaikan secara kontinyu.

\section{Analisis SWOT DW Kreasi}

Tabel 1. Analisis SWOT DW Kreasi

\begin{tabular}{lll}
\hline \multicolumn{1}{c}{ Strength : } & \multicolumn{2}{c}{ Weaknesses : } \\
\hline $\begin{array}{l}\text { Menggunakan mesin sendiri sehingga } \\
\text { dapat menekan biaya produksi dan } \\
\text { mempermudah mengontrol kualitas. }\end{array}$ & $\begin{array}{l}\text { Produk hanya mengandalkan fungsi } \\
\text { tanpa estetika } \\
\text { Desain monoton }\end{array}$ \\
- Tempat Produksi Sendiri & & \\
- Memiliki hak paten & & \\
- Menggunakan material local grade \\
terbaik
\end{tabular}

Sumber: Hasil wawancara 
Tabel 2. Faktor Internal dan Eksternal DW Kreasi

Faktor Internal

- Memiliki tempat produksi sendiri

- Memiliki mesin produksi sendiri

- Memiliki karyawan professional dibidangnya

- Desain produk nya monoton

- Menggunakan material grade terbaik

- Desain produk dibuat sendiri

- Memliki hak cipta

- Lokasi penjualan strategis
Faktor Eksternal

- Bahan material mudah didapatkan

- Munculnya produk sejenis

Tabel 3. IFAS DW Kreasi

\begin{tabular}{|c|c|c|c|c|}
\hline & IFAS & Bobot & Rating & Skor \\
\hline Streng & & & & \\
\hline S.1 & $\begin{array}{l}\text { Menggunakan mesin sendiri sehingga } \\
\text { dapat menekan biaya produksi dan } \\
\text { mempermudah mengontrol kualitas. }\end{array}$ & 0.16 & 4 & 0,64 \\
\hline S.2 & Tempat Produksi Sendiri & 0.08 & 2 & 1.6 \\
\hline S.3 & Memiliki hak paten & 0.10 & 3 & 0.3 \\
\hline S.4 & Menggunakan material local grade terbaik & 0.15 & 3 & 0.45 \\
\hline S.5 & Membuat desain produk sendiri & 0.10 & 2 & 0.2 \\
\hline S.6 & Pekerja yang professional & 0.15 & 4 & 0.6 \\
\hline & Sub Total Strength & 0.74 & & 3.79 \\
\hline Weakr & & & & \\
\hline W.1 & $\begin{array}{l}\text { Produk hanya mengandalkan fungsi } \\
\text { tanpa mempertimbangkan keunikan } \\
\text { tampilan/visualnya. }\end{array}$ & 0.17 & 3 & 0.51 \\
\hline W.2 & Desain itu - itu saja & 0.13 & 2 & 0.26 \\
\hline & Sub Total Weakness & 0.30 & & 0.77 \\
\hline & Total & 1,04 & & 4,0 \\
\hline
\end{tabular}

Sumber: Data primer diolah

Tabel 4. EFAS DW Kreasi

\begin{tabular}{lllll}
\hline \multicolumn{1}{c}{ EFAS } & Bobot & Rating & Skor \\
\hline Opportunities & & & \\
\hline S.1 & Lokasi penjualan strategis & 0.12 & 3 & 0.36 \\
S.2 & Mukena adalah pakaian fungsional yang & 0.16 & 4 & 0.64 \\
& $\begin{array}{l}\text { akan selalu dibutuhkan oleh Muslimah } \\
\text { Indonesia. }\end{array}$ & & & \\
\hline
\end{tabular}




\begin{tabular}{|c|c|c|c|c|}
\hline & Sub Total Opportunities & 0.28 & & 1 \\
\hline \multicolumn{5}{|c|}{ Threats } \\
\hline W.1 & $\begin{array}{l}\text { Banyak pesaing yang menjual produk } \\
\text { serupa dan memiliki estetika }\end{array}$ & 0.10 & 1 & 0.10 \\
\hline \multirow[t]{3}{*}{ W.2 } & $\begin{array}{l}\text { Pesaing dapat bekerja sama dengan } \\
\text { influencer untuk mempromosikan } \\
\text { produknya }\end{array}$ & 0.12 & 2 & 0.24 \\
\hline & Sub Total Threats & 0.22 & & 0.34 \\
\hline & Total & 0.5 & & 1,34 \\
\hline
\end{tabular}

Sumber: Data primer diolah

Berdasarkan perhitungan penilaian pada tabel IFAS maka didapatkan total skor untuk menentukan titik pertumbuhan pada UKM Dw Kreasi.

Tabel 5. Matriks IE DW Kreasi

SKOR BOBOT TOTAL IFES

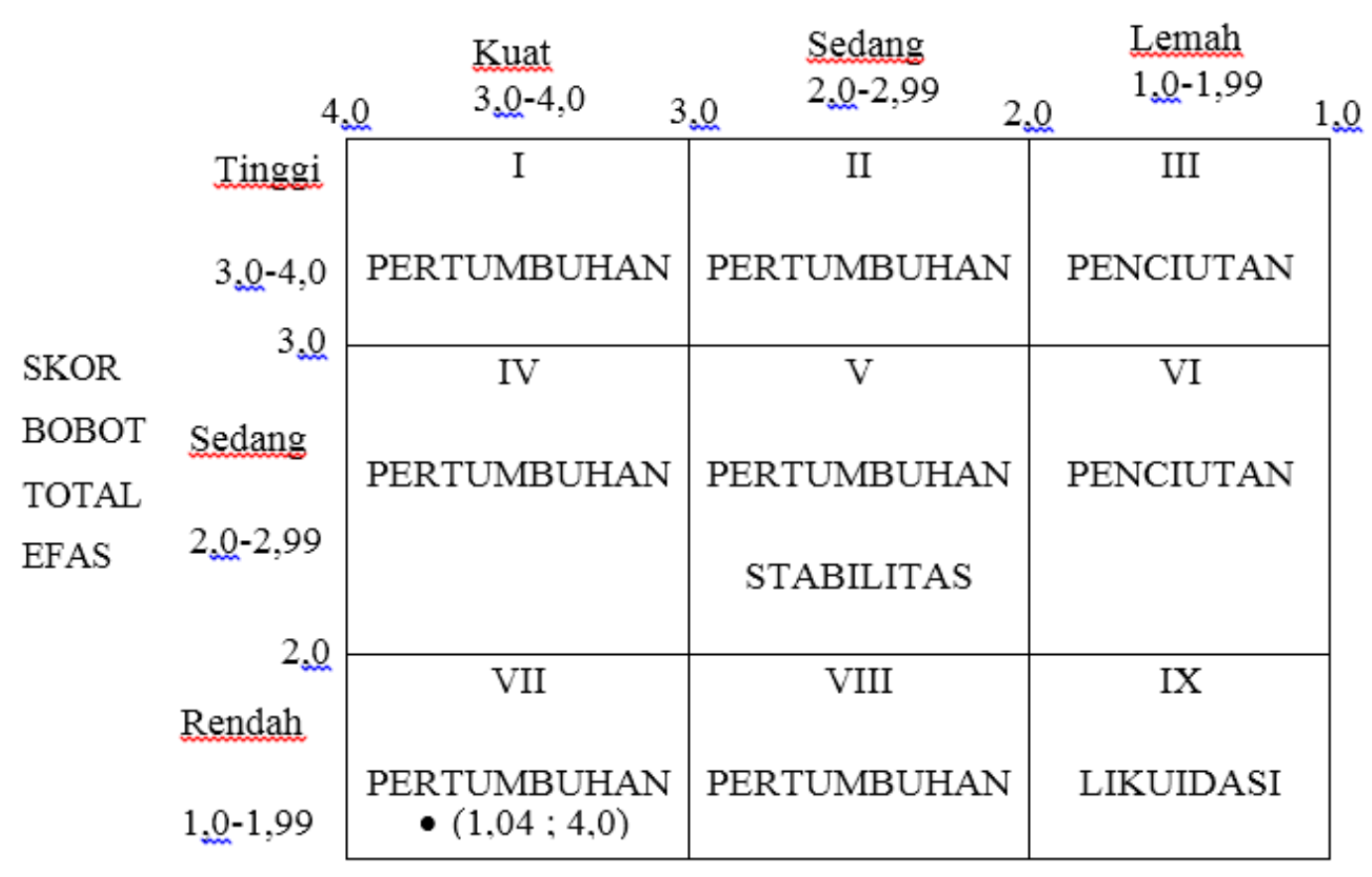

Berdasarkan analisis matriks IE maka dapat disimpulkan DW kreasi menggunakan strategi sebagai berikut :

1. Membuat pengembangan pada produk

2. Meningkatkan promosi melalui influencer

3. Meminimalisir penggunaan bahan baku jika harga bahan baku mahal 
Tabel 6. Strategi SW- ST- WT UKM DW Kreasi

\begin{tabular}{|c|c|c|}
\hline & $S$ & $\mathbf{W}$ \\
\hline $\mathrm{O}$ & \begin{tabular}{l}
\multicolumn{1}{c}{ SO } \\
- \\
Membuat produk dengan desain \\
baru \\
- \\
pempertahankan sarana \& \\
meningkatkan kualitas produk.
\end{tabular} & $\begin{array}{l}\text { WO } \\
\text { - } \quad \text { Memperbolehkan membuat } \\
\text { produk custom } \\
\text { - Melakukan kegiatan promosi } \\
\text { untuk memperluas pangsa } \\
\text { pasar }\end{array}$ \\
\hline $\mathbf{T}$ & $\begin{array}{l}\text { ST } \\
\text { - Melakukan inoovasi-inovasi baru } \\
\text { pada bisnis }\end{array}$ & $\begin{array}{l}\text { WT } \\
\text { - Melakukan pengembangan } \\
\text { usaha }\end{array}$ \\
\hline
\end{tabular}

\section{Analisis BCG}

Data yang digunakan untuk matriks BCG (Boston Consulting Group) adalah data volume penjualan UKM DW Kreasi dan total volume penjualan Naisha Hijrah ( pesaing ) sebagai berikut :
a. Gamis : Rp. 220.000
b. Jilbab Anak : Rp. 35.000
c. Jilbab Dewasa : Rp. 60.000
d. Mukena : Rp. 160.000

Tabel 7. Data Penjualan DW Kreasi 2018

\begin{tabular}{lcc}
\hline ATPM & $\begin{array}{c}\text { Penjualan Januari s/d } \\
\text { Desember 2018 }\end{array}$ & $\begin{array}{c}\text { Market } \\
\text { Share }\end{array}$ \\
\hline Gamis & 232.736 .703 & $63,26 \%$ \\
Jilbab Anak & 26.673 .112 & $7,25 \%$ \\
Jilbab Dewasa & 55.664 .026 & $15,13 \%$ \\
Mukena & 52.831 .158 & $14,36 \%$ \\
\hline
\end{tabular}

Sumber: Data Penjualan DW Kreasi (2018)

Tabel 8. Data Penjualan DW Kreasi 2019

\begin{tabular}{lcc}
\hline \multicolumn{1}{c}{ ATPM } & $\begin{array}{c}\text { Penjualan Januari s/d } \\
\text { Desember 2019 }\end{array}$ & Market Share \\
\hline Gamis & 180.632 .816 & $61,52 \%$ \\
Jilbab Anak & 59.991 .876 & $12,78 \%$ \\
Jilbab Dewasa & 67.314 .828 & $14,34 \%$ \\
Mukena & 53.326 .112 & $11,36 \%$ \\
\hline
\end{tabular}

Sumber: Data Penjualan DW Kreasi (2019) 
Tabel 9. Data Penjualan Naisha Hijab 2019 (Pesaing)

\begin{tabular}{lcc}
\hline \multicolumn{1}{c}{ ATPM } & $\begin{array}{c}\text { Penjualan Januari } \\
\text { s/d Desember } \\
\mathbf{2 0 1 9}\end{array}$ & Market Share \\
\hline Gamis & 304.497 .388 & $60,69 \%$ \\
Jilbab Anak & 74.875 .480 & $14,90 \%$ \\
Jilbab Dewasa & 69.800 .028 & $13,89 \%$ \\
Mukena & 53.367 .624 & $10,62 \%$ \\
\hline
\end{tabular}

Sumber: Data Penjualan Naisha Hijab 2019 (Pesaing)

Perhitungan Tingkat Pertumbuhan Pasar (Market Grow Rate)

Maka hasil perhitungan tingkat pertumbuhan pasar dari UKM DW Kreasi yaitu :

$$
T P P=\frac{\mathrm{VPN}-\mathrm{VPN}-1}{\mathrm{VPN}-1} \times 100 \%
$$

TPP = Tingkat Pertumbuhan Pasar

VPN =Volume Penjualan Perusahaan tahun Terakhir

VP N - 1 =Volume Penjualan Perusahaan Tahun Sebelumnya

\section{Gamis}

$$
T P P=\frac{288.750 .000-232.750 .000}{232.750 .000} \times 100 \%=0,24 \%
$$

\section{Jilbab Anak}

$$
T P P=\frac{60.000 .000-52.800 .000}{52.800 .000} \times 100 \%=13,63 \%
$$

3. Jilbab Dewasa

$$
T P P=\frac{67.320 .000-55.680 .000}{55.680 .000} \times 100 \%=20 \%
$$

\section{Mukena}

$$
T P P=\frac{53.350 .000-26.675 .000}{26.675 .000} \times 100 \%=1 \%
$$

Hasil perhitungan tingkat pertumbuhan didapatkan penjualan Gamis 0,24\%, Jilbab Anak 13,63\%, Jilbab Dewasa 20\%, Mukena 1\%. Dalam matriks BCG DW Kreasi memiliki tingkat perumbuhan pasar yang tinggi, terlihat dari kenaikan penjualan dari tahun 2018-2019. 


\section{Pangsa Pasar Relatif}

$$
P P R=\frac{\mathrm{VPN}}{\mathrm{VPPN}}
$$

$$
\begin{array}{ll}
\text { PPR } & =\text { Pangsa Pasar Relative } \\
\text { VPN } & =\text { Volume Penjualan Tahun Terakhir } \\
\text { VPPN } & =\text { Volume Penjualan Pesaing Tahun Terakhir }
\end{array}
$$

\section{Gamis}

$$
P P R=\frac{298.899 .000}{301.000 .000}=1
$$

2. Jilbab Anak

$$
P P R=\frac{60.000 .000}{74.880 .000}=0,80
$$

\section{Jilbab Dewasa}

$$
P P R=\frac{67.320 .000}{69.840 .000}=0,96
$$

\section{Mukena}

$$
P P R=\frac{53.350 .000}{52.800 .000}=1,01
$$

Hasil perhitungan tingkat pangsa pasar relative DW Kreasi dibandingkan dengan perusahaan pesaing sebesar 0,95, 0,80, 0,96, 1,01 menjukan bahwa DW Kreasi memiliki pangsa pasar rendah dibandingkan perusahaan pesaing karena nilai pangsa pasar relative kurang dari 1.

\section{Pembahasan}

\section{Konsep Desain}

Mukena Bilqis adalah busana muslim yang meniliki fungsi untuk beribadah, Mukena dengan tas yang multifungsi. Yakni selain untuk menyimpan mukena juga bisa digunakan untuk sajadah yang nyaman karena pada bagian tengah dilapisi busa angin dan tidak perlu khawatir permukaan yang digunakan untuk shalat kotor karena ketika tas dibuka bagian dalam tas akan menjadi alas/sajadah dan bagian luar tas sebagai alas bawah sajadah. Mukena menggunakan warna yang soft serta bahan katun SBY yang halus, tidak mudah kusut dan tidak membuat gerah.

Di produksi langsung oleh UKM Dw Kreasi menggunakan mesin jahit khusus dan pengrajin yang terampil. Di peruntukan untuk wanita muslimah usia 18-30th suka berpergian, pelajar/pekerja, perekonomian menengah ke atas dan bertempat tinggal di kota besar (Jakarta, Bandung, Denpasar, Aceh, dll). Produk ini meliputi mukena dan tas, dijual di ; Department Store, outlet perlengkapan ibadah, dan toko Dw Kreasi. Dengan harga kisaran Rp. 300.000. 


\section{Penutup}

Mukena Balqis di rancang berdasarkan hasil observasi pada UKM Dw Kreasi, matriks SWOT dan matriks BCG yang kemudian di olah ke dalam Scamper menggunakan metode combine, adapt, dan modify kemudian di terapkan ke dalam desain. Hasilnya adalah mukena dengan tas multifungsi yakni selain sebagai tempat penyimpanan mukena tas juga dapat digunakan untuk sajadah sehingga memudahkan pengguna untuk manjalankan shalat dimanapun. sebagai pengembangan dari produk yang sebelumnya yang hanya mukena dan tas saja tanpa ada fungsi yang lainnya sehingga dapat memenuhi kebutuhan konsumen sehingga akan menunjang kelangsungan UKM Dw Kreasi. Ibu Asriani selaku Owner dari Dw Kreasi juga ikut terlibat dalam pemilihan desain yang nanti nya akan di produksi masal.

\section{Referensi}

Amirullah, S. E., \& Strategi, M. M. (2015). Teori-Konsep-Kinerja. Jakarta: Mitra Wacana Media.

Jauhari, J. (2010). Upaya pengembangan usaha kecil dan menengah (UKM) dengan memanfaatkan e-commerce. Jurnal Sistem Informasi, 2(1), 1-12.

Mirantika, N., \& Marbun, S. (2016). Pengaruh Modernisasi Terhadap Perkembangan Komodifikasi Mukena (Vol. 1). An1mage.

Rangkuti, F. (2004). Analisis SWOT teknik membedah kasus bisnis. Gramedia Pustaka

Sarjono, H., \& Kuncoro, E. A. (2013). Analisis Matriks Boston Consulting Group (BCG) untuk Memenangkan Strategi Organisasi (Studi Kasus Perguruan Tinggi Di Kopertis Wilayah III-DKI Jakarta). Binus Business Review, 4(1), 414-422.

Siswoyo, A. A. (2017). Analisis Kebutuhan SI/TI untuk Mendukung Proses Bisnis Usaha Kecil pada Industri Garmen di Jawa Timur dengan Metode Business Object Oriented Modeling (Multi Studi Kasus) (Doctoral dissertation, Institut Teknologi Sepuluh Nopember). 